\title{
EL DIFÍCIL CONTEXTO POLÍTICO DE LA UNIVERSIDAD DE CHILE
}

Carlos Huneeus Madge 


\section{CARLOS HUNEEUS MADGE}

Abogado. Máster en Comportamiento político, Universidad de Essex (Inglaterra), Ph.D. en Ciencia Política, Universidad de Heidelberg (Alemania). Profesor asociado del Instituto de Estudios Internacionales de la Universidad de Chile. Áreas de interés: Política comparada, democratización, cultura cívica, el sistema político de Chile. 


\section{EL DIFÍCIL CONTEXTO POLÍTICO \\ DE LA UNIVERSIDAD DE CHILE}

Las dificultades institucionales y las limitaciones económicas que enfrenta la Universidad de Chile se entrecruzan con la accidentada y dramática historia del país en las últimas décadas y con una tardía, rápida y convulsionada modernización, que terminaría con el desplome de la democracia en 1973 y el establecimiento de un régimen autoritario del general Augusto Pinochet (1973-1990). Este fue un Estado dual, pues junto a la aplicación de una dura coerción, que causó enormes heridas en la sociedad, impulsó una transformación económica de orientación neoliberal, con objetivos fundacionales, desmantelando las raíces del Estado y la sociedad, que abarcó la educación, incluida la superior, y estableció nuevos fundamentos para ellos. Este tipo de régimen no se dio en ningún otro país donde se hayan extendido los "nuevos autoritarismos" en América Latina en esos años, desde el Golpe militar en el Brasil de 1964 (Collier, 1979)1. Esta transformación no fue alterada en sus fundamentos con el restablecimiento de la democracia en 1990, logrando fortalecer algunas de sus áreas.

\section{LAS CONSECUENCIAS DE LA TARDÍA MODERNIZACIÓN DE CHILE}

La profundidad de la ruptura producida por los nuevos gobernantes de 1973 y su impacto en la Universidad de Chile se explica no solo como una reacción a las políticas del Gobierno de la Unidad Popular del presidente Salvador Allende (PS) (1970-1973), que se propuso construir el socialismo por la vía legal teniendo el apoyo de una minoría del electorado, sino también a las impulsadas por el Gobierno del presidente Eduardo Frei Montalva (PDC) (1964-1970), que enfrentó la "crisis integral" (Ahumada, 1957) con una economía subdesarrollada, con la mayoría de la población viviendo en condiciones de pobreza, con una agricultura incapaz de satisfacer las necesidades de alimentación de los chilenos y con una democracia de participación limitada, porque una minoría de la población adulta estaba inscrita en los registros electorales y eran ciudadanos.

El desarrollo político que había tenido Chile fue excepcional en la región en la que predominó la hegemonía militar (Rouquié, 1984; 2011), por la continuidad de gobiernos elegidos en elecciones competitivas, sistema de partidos y Estado de derecho, que llevó a que Aníbal Pinto (1958) lo calificara como un "sobrecrecimiento político". Sin embargo, este desarrollo tenía importantes limitaciones en su calidad, porque una minoría de los adultos tenía derechos políticos y una parte de la población, los campesinos, carecían de derechos civiles y políticos hasta comienzos de los años 60. La alta tasa de analfabetismo les impedía ser ciudadanos, porque se requería saber leer y escribir

1. Esto lo desarrollo en Huneeus (2000). 
para serlo -solo en 1970 se dio derecho a voto a los analfabetos- y les estaba prohibido organizarse en sindicatos. No existía organización en los sectores populares para articular sus demandas ante el Estado para que atendiera sus necesidades.

A diferencia de otros países en América Latina, como Argentina y Uruguay, Chile enfrentó tardíamente su modernización económica y política y ello no podía dejar de tener altos costos para el país, porque debió enfrentar simultáneamente desafíos que estos pudieron resolver gradualmente. Chile pasó de una democracia de participación limitada a una de participación amplia desde fines de los años 40 con la incorporación de: la mujer, los sectores populares (especialmente campesinos), y la juventud, expandiendo fuertemente, con profundas repercusiones en el sistema de partidos. Además, debió enfrentar los desafíos de la modernización en el campo, largamente postergada por los gobiernos de distinta orientación política, y también encaró la integración de los sectores populares urbanos, expandidos en número por la urbanización, y se esforzó por superar el subdesarrollo. Lo anterior lo realizó en el contexto de la Guerra Fría, que repercutió en el proceso político chileno, con el conflicto entre EE.UU. y la Unión Soviética, y con una Revolución cubana que fue considerada como un modelo a seguir por sectores de la juventud del PDC y del PS, llevándolos a adoptar posiciones maximalistas, rechazando las bases de la democracia y cuestionando las políticas que seguían sus respectivas colectividades, lo que contribuyó a polarizar el proceso político. El discurso y la acción de estos acentuó las posiciones anticomunistas en las colectividades de derecha, que consideraban al comunismo como el principal problema del país, y no las causas estructurales, económicas, sociales y políticas que explicaban que el PC tuviera un considerable apoyo electoral, llegando tercero en importancia en el mundo de las entonces democracias pluralistas. El impacto de la revolución cubana en sectores de la juventud del PDC produjo efectos muy negativos en el Gobierno de Frei, el que debió enfrentar una oposición interna que descalificaba su propuesta reformista como reaccionaria y planteaba como alternativa formar "un frente revolucionario", confirmando las acusaciones de la derecha de que el PDC abría el paso al comunismo ${ }^{2}$.

El contexto de la modernización impulsada por el Gobierno de Frei tuvo mayores costos políticos porque los partidos de derecha, conservadores y liberales, estaban muy debilitados como organización y ante el electorado ${ }^{3}$, luego del desplome de su candidatura presidencial en 1964, junto al PR, y en las parlamentarias de 1965, cayendo el electorado de los antiguos pipiolos y conservadores al 12,5\% de los votos, siendo absorbido

2. La radicalización de la JDC adquirió una orientación ideológica ajena a su doctrina, pues se identificó con el marxismo y el leninismo, planteando la estrategia del "frente revolucionario", una alternativa distinta a la del Frente Popular o Unidad Popular que proponía el PC y Salvador Allende. En noviembre de 1968, seis meses antes de romper con el PDC y formar el MAPU, en su informe político al consejo plenario de la JDC, su presidente, Enrique Correa, proponía la estrategia del "frente revolucionario", que incluía un acuerdo con el MIR. Esto se plantea en el documento del mismo, "iA terminar con los momios estén donde esténi", aludiendo a los que se encontrarían en el partido al cual pertenecían y estaban en el Gobierno.

3. Seguimos la diferenciación de Dalton y Wattenberg (2002). 
por el emergente Partido Demócrata Cristiano. Este debilitamiento fue acelerado con el Gobierno del empresario independiente Jorge Alessandri, quien llegó a La Moneda en 1958 con el menor apoyo electoral de los mandatarios desde 1931, 34,6\% de los votos, y su Gobierno no fue capaz de enfrentar los desafíos que tenía el país. Ambas colectividades se fusionarán en 1966 en el Partido Nacional. Esta fusión será más que la unión de estas, pues integrará a grupos y personalidades que habían tenido una actitud crítica a la democracia y a los partidos desde los años 40 , mirando con interés la experiencia española del corporativismo del régimen autoritario del general Francisco Franco. Fuera del PN actuarán personalidades independientes en torno al ex presidente Alessandri, que cuestionaban no solo el rol de los partidos, sino también el rol del Congreso. Unos y otros colaborarán con los militares después de la toma del poder en 1973 y tendrán la posibilidad de influir en su programa político, especialmente en la Constitución de 1980.

Destacó en la gestión del Gobierno de Frei la reforma agraria y la sindicalización campesina, que tuvieron un profundo impacto económico y político. Sus consecuencias desbordaron sus objetivos, porque sus beneficiarios plantearon nuevas demandas al sistema político y porque los perjudicados, quienes fueron expropiados de los fundos y haciendas, no permanecerían impasibles ante este cambio y radicalizaron sus aspiraciones políticas hacia posturas críticas a la democracia. La sindicalización campesina había roto el acuerdo de élites que había existido de prohibir los sindicatos en el campo, respetado hasta por el Gobierno del Frente Popular (1938-1941) del presidente Pedro Aguirre Cerda (PR) ${ }^{4}$. En consecuencia, la dinámica de politización y polarización en Chile desde mediados de los años 60 no fueron las causas de la crisis de la democracia, sino más bien la consecuencia de no haberse enfrentado antes.

Los procesos de modernización, escribió Samuel P. Huntington (1968), se caracterizan por expandir sus consecuencias al conjunto de la sociedad, con un aumento de la politización en los distintos subsistemas, la ciudad, el campo, los jóvenes y adultos, las universidades y hasta los militares. No hay partes del país que puedan mantenerse alejadas del impacto de la modernización.

El proceso de modernización llegó a las universidades por intermedio del liderazgo del movimiento estudiantil a través de sus federaciones, que recogían su larga tradición de identificación con los problemas del país y de vinculación con los partidos, y de los académicos, especialmente los jóvenes, que aspiraban a tener mayor participación en el gobierno de la universidad ${ }^{5}$. Por su magnitud, complejidad institucional, pluralismo político en sus estudiantes y académicos y por su importancia nacional, la reforma de la Universidad de Chile tuvo características que excedieron por lejos la que caracterizó antes a la Universidad Católica de Valparaíso y a la Universidad Católica de Chile. Estas últimas tuvieron una reforma que logró consolidarse con relativa facilidad, favorecidas por su menor tamaño, su homogeneidad social y política (estudiantes de colegios

4. Esto he analizado en Huneeus (2009).

5. He analizado la reforma de la Universidad de Chile (Huneeus, 1973) y del proceso de reforma de las universidades (Huneeus, 1988). 
católicos y de estratos medio-altos y altos) y su identidad religiosa. La Universidad de Chile, por el contrario, tuvo una larga y difícil reforma, en la que la definición por el gobierno de ella se cruzó con distintas concepciones sobre su rol en el país. Para sectores conservadores, la reforma universitaria fue vista como una expresión intolerable de la evolución política del país, que confirmaba que las universidades estarían siendo conducidas en un espiral de politización que terminaría siendo controlado por "el comunismo".

\section{LA UNIVERSIDAD DE CHILE EN LA FORMACIÓN DEL ESTADO NACIONAL}

La Universidad de Chile no se mantuvo ajena a las tensiones que convulsionaron al país desde los años 60 , porque su historia estaba unida a la formación de la República, que le asignó al fundarla en 1842 no solo las tareas propias de formación de profesionales y desarrollo de la ciencia, sino también dirigir la educación pública (Serrano, 1993). La educación impartida por el Estado era la principal del país, pues los forjadores de la República decidieron que la educación debía ser estatal, quedando ello establecido en la Constitución de 1833, que determinó que la educación es "una atención preferente del Estado". Se identificaba, así, el desarrollo del Estado nacional con la Universidad de Chile, que le daría a esta un sello especial y que perduraría hasta el quiebre producido en 1973 con el Golpe militar y el afán refundacional de los nuevos gobernantes.

En su larga historia, la Universidad de Chile ha sido el eje en el desarrollo de la educación superior. Por sus aulas se graduaron los profesionales que han servido al país en los distintos ámbitos, lo cual reafirmaba su pluralismo: desde presidentes y parlamentarios de todos los partidos, hasta científicos y poetas que forman parte del patrimonio del país. Se esforzó por ser una institución cercana a las necesidades del país, entendiendo así su función pública, y fue pluralista en la formación de sus alumnos y en su orientación científica, que le permitió tener un rol de liderazgo durante su larga historia.

Esa posición dominante la mantuvo más allá de los cambios en el sistema de educación superior, que comenzaría a fines del siglo XIX con la fundación de la Universidad Católica, por iniciativa de católicos ante la fuerza de las ideas liberales. Profesores de la Universidad de Chile ayudarán al desarrollo de las facultades en las nuevas universidades, como el Dr. Héctor Croxatto, uno de los más destacados ayudantes del Dr. Eduardo Cruz-Coke, quien se trasladó a la Universidad Católica a colaborar en la creación de su escuela de Medicina, luego de que el rector de esta, Mons. Carlos Casanueva, le pidiera ayuda al Dr. Cruz-Coke.

Esta posición también se mantendría con ocasión del segundo cambio importante de la educación superior, con la expansión de la matrícula desde fines de los años 50 y especialmente durante los años 60, con su extensión a las regiones, creando sedes desde Arica a Osorno para ser una Universidad nacional. Fue una época en que se produjo un fuerte aumento del acceso de las mujeres a las universidades, cambio en el cual la Universidad de Chile tuvo un rol muy activo. 
La educación no era el único ámbito en que el Estado tenía un rol fundamental como organizador y supervisor de ella. También lo era en la política de salud, con la creación de hospitales desde el siglo XIX y una institucionalidad que permitiera el acceso a ella de los sectores medios y populares, con políticas que sobresalieron en el contexto latinoamericano por sus indicadores desde la mortalidad infantil, hasta las expectativas de vida (Jiménez de la Jara, 2007). Médicos de la Universidad de Chile tuvieron un rol fundamental en el desarrollo de esta política de salud, que fue impulsada activamente por políticos del partido conservador, como los doctores Exequiel González Cortés, Eduardo Cruz-Coke y Jorge Mardones Restat, quien, como Ministro de Salud a finales del Gobierno de Gabriel González Videla (1946-1952), lograría que el Congreso aprobara el proyecto de ley que creo el Servicio Nacional de Salud (SNS), que organizaría el sistema público de salud y permitiría un mejor desarrollo de este.

Educación y salud eran las columnas vertebrales del Estado benefactor que tuvo Chile, que se complementaba con el sistema de seguridad social y de previsión. El Estado benefactor se basó en un amplio consenso político, desde la derecha hasta la izquierda, comparable al "consenso social demócrata" que Ralf Dahrendorf (1979) consideró la clave del que hubo en Europa después de la II Guerra Mundial. Este no fue cuestionado en Chile antes del régimen militar, por tener esta amplia base de legitimación, y además mostraba logros importantes, especialmente en salud pública, que sobresalían en el contexto internacional de la Organización Mundial de Salud (OMS) por ser un país en subdesarrollo (Jiménez de la Jara, 2010).

\section{LA RUPTURA DE 1973 Y SU IMPACTO EN LA UNIVERSIDAD DE CHILE}

La coalición de militares y civiles formada luego del Golpe de Estado de 1973 y que formaría el régimen político, tuvo aspiraciones fundacionales desde muy temprano. Junto con buscar superar la gravísima crisis económica producida por el Gobierno de la Unidad Popular, con una hiperinflación y el desplome del sistema productivo que agravaron la crisis política, se propusieron objetivos de largo plazo, entre ellos: establecer un nuevo orden económico y político que llevara al desarrollo y que perduraría después de que los militares regresaran a sus cuarteles. Este objetivo no contemplaba el restablecimiento de la democracia, con las rectificaciones institucionales que evitaran las debilidades que llevaron a su desplome, sino, por el contrario, la implantación de un régimen político distinto, "la democracia protegida y autoritaria", en el cual los partidos políticos "no tuvieran el monopolio de la representación política" y el Congreso tuviera un rol subordinado, frente a un presidente que concentraría el poder.

Este afán refundacional se apoyaba en una evaluación muy crítica del desarrollo político y social del país, que estaría aquejado de una "decadencia", y fue provocado en buena medida por los partidos, que consideraban que la democracia era "débil" para enfrentar las amenazas de sus "enemigos", el comunismo y, más tarde, el terrorismo. El bombardeo del palacio de La Moneda, el símbolo de la democracia, por los aviones de la Fuerza Aérea, fue la inmediata expresión de esa voluntad, reiterada luego por el anuncio 
de erradicar "el cáncer marxista", calificando como enemigos a sus adversarios, y la destrucción de los registros electorales, otro rechazo a la tradición democrática de Chile.

Estas manifestaciones de violencia desde arriba estimularon el empleo de violencia desde abajo por efectivos militares y carabineros en poblaciones populares, industrias y recintos universitarios que produjeron muertos, y tendría luego su expresión institucionalizada a través de sus servicios de seguridad.

Fue una toma del poder muy distinta a la que hubo en los otros "nuevos autoritarismos", en que los militares no emplearon este tipo de violencia desde arriba. Fue el caso del Perú en 1968, pues los militares sacaron al presidente Fernando Belaúnde en la madrugada del 21 de octubre de 1968 y lo subieron a un avión, enviándolo al extranjero ${ }^{6}$.

El programa de refundación económica se construyó a partir de una visión neoliberal de la economía y el Estado, rechazando el Estado benefactor, que había permitido atender derechos sociales (Marshall, 1973), y el Estado empresario, surgido en los años 40 con importantes empresas públicas que enfrentan las necesidades de energía, siderurgia, telecomunicaciones, petroquímica y otras en los esfuerzos hechos por los gobiernos de la época para industrializar al país. Ambos serían desmantelados antes de que los militares volvieran a sus cuarteles en 1990.

Esta refundación iba más allá de desmantelar las instituciones creadas por el Estado en la economía, la educación y la salud, pues también buscaba redefinir los valores de los chilenos, todo lo cual apuntaba a imponer la primacía del interés individual, pues se reduciría en forma gradual, pero persistente el espacio del "dominio público" (Marquand, 2004), que sería sustituido por otro, el "espacio privado". Este último es bastante más amplio que el sector público, formado por empresas e instituciones del Estado, pues su identificación se construye a partir de valores y objetivos "públicos" y su límite está constituido por el interés privado y el mercado. El dominio público está ligado a "los valores de ciudadanía, igualdad y servicio [ y ] los bienes son distribuidos de acuerdo a las necesidades y no a lazos personales o acceso a recursos económicos" (Marquand, 2004, pág. 27). Es un espacio complejo de definir, pero es claro cuáles son los espacios ajenos a este: el mercado y el espacio dominado por los privados. (Marquand, 2004, pág. 27). En consecuencia, el desmantelamiento del "dominio público" abarca instituciones que se encuentran en el corazón del Estado y también abarca un cambio de valores. Buscaba que el interés privado tuviera una posición institucional dominante en el Estado y en la economía y, aun más, que la política tuviera una baja autonomía de los intereses privados.

Esto se tradujo en: el desmantelamiento del Estado benefactor, con la privatización de la seguridad social y el surgimiento de las Isapres, el fin del sistema previsional, reemplazándolo por el de capitalización individual en las AFP y un descuido en las inversiones hacia el sistema público de salud, especialmente los hospitales, por el convencimiento de que el futuro apuntaba hacia corporaciones privadas más eficientes ${ }^{7}$.

\footnotetext{
6. En Argentina, los militares de los años 60 derribaban a presidentes (Arturo Frondizi en 1963 y Arturo Illía en 1966), que eran enviados a una isla en el río de la Plata.

7. Hemos analizado las privatizaciones del régimen militar en Huneeus (2007).
} 
El desmantelamiento del Estado empresario se hizo a través de la privatización de las empresas públicas de tal manera que benefició a sus altos ejecutivos, que ocuparon esas posiciones porque gozaban de la confianza de las autoridades y se convirtieron en sus socios controlados en empresas de importantes sectores, desde la petroquímica y la metalurgia, hasta la energía y las telecomunicaciones. La concentración del poder político y económico que caracterizó al autoritarismo llevó a la fusión de los intereses públicos y privados en beneficio de estos últimos, y permitió este tipo de privatización, muy distinta a las que se realiza en democracia, que divide el poder público y privado y separa sus intereses para proteger al Estado.

La educación formó parte de este plan refundacional por su importancia política en la formación de niños, jóvenes y adultos, y por las implicancias económicas que ella tiene, como industria en la cual se puede extender el espíritu capitalista. Esto se tradujo en una iniciativa de alejamiento gradual del "dominio público", a través de sucesivas etapas, comenzando con la fragmentación institucional de la educación básica y media a través de su municipalización, sin entregarle a los municipios los recursos institucionales y económicos para llevar adelante una labor de calidad, siguiendo luego con la privatización de la educación superior a través de la ley de 1980, que se proponía introducir un nuevo pilar en el sistema universitario, junto a las universidades estatales y privadas del Consejo de Rectores.

La imposición del autofinanciamiento universitario fue una parte de la ingeniería política destinada a reducir el espacio público e imponer el dominio privado en el ámbito de la educación superior, pues les obligaba a irrumpir en el del mercado y atender los intereses privados y los principales actores las consideraban instituciones ajenas, que debían ser sustituidas por universidades privadas. El autofinanciamiento acentuó los desequilibrios al interior de las universidades estatales. Las facultades más grandes eran las que tenían más posibilidades de acceder a contratos privados o a donaciones, agravando desigualdades internas que las han dañado aun más.

La Universidad de Chile fue duramente golpeada por este plan refundacional. Los nuevos gobernantes tenían una actitud agresiva contra ella; por sus intereses ideológicos contra el Estado y por su rechazo a la reforma universitaria. Desde un comienzo se le buscó reducir en forma drástica su tamaño y sus funciones. A diferencia de la Universidad Católica, cuyo gobierno fue asumido por un grupo de poder interno formado por estudiantes y académicos, bajo el liderazgo del "gremialismo", que apoyó a las nuevas autoridades del país y aportó profesionales que asumieron diversos puestos en el gobierno, llegando a ser el principal grupo de poder civil, la Universidad de Chile fue considerada como una institución adversaria, siendo dirigida por rectores militares, varios en servicio activo, que no estaban empeñados en modernizar su organización y mejorar las condiciones de su funcionamiento.

Mientras "el gremialismo" lograba que el Gobierno respaldara a la UC para que creciera y llegara a tener un tamaño que le permitiera tener un rol de liderazgo en la educación superior, con la Universidad de Chile los nuevos gobernantes se propusieron reducir su tamaño, para que dejara de ser un actor dominante en la educación superior, la investigación científica y el desarrollo cultural del país. Junto a la limpieza ideológica 
del cuerpo académico, especialmente en las Ciencias Sociales, la Universidad fue luego privada del Instituto Pedagógico, que fue separado y transformado en otra universidad pública, y separada de las sedes regionales, que habían sido creadas desde los años 50 en diversas ciudades del país para cumplir su carácter de institución nacional. La mala gestión de las autoridades designadas por el régimen militar creó debilidades organizativas que la dañarían aun más.

Con la inauguración de la democracia en 1990, no hubo una estrategia por la coalición de centro e izquierda para enfrentar la reducción del "espacio público" y reconstruirlo. Por el contrario, se dio continuidad y hasta se profundizó el dominio privado en la educación, que se extendería a la política de vivienda durante el Gobierno de Ricardo Lagos, el primer mandatario socialista después de Salvador Allende.

De ahí que, en 1990, la Universidad de Chile enfrentara un escenario extraordinariamente difícil. Internamente era muy distinta a la que fue hasta 1973, con profundas heridas que le impedían seguir adelante con la eficacia exigida por sus enormes falencias, y tenía que actuar en un sistema político en el cual la élite de Gobierno y del Congreso tenía intereses ajenos a ella y también distintos a los que tuvieron en el pasado el PDC, el PR y la izquierda. La formación del primer Gobierno democrático aparecía auspicioso para la Universidad. El presidente Aylwin era ex alumno y había sido profesor desde que terminó sus estudios, dos ministros habían sido autoridades, el ex rector Edgardo Boeninger (ministro Secretario General de la Presidencia) y Ricardo Lagos (Secretario General), ministro de Educación y casi todos los ministros eran egresados de ella y habían sido profesores durante largos años ${ }^{8}$. Sin embargo, esas condiciones no eran suficientes para contrarrestar la profundidad de los cambios institucionales que provocó el largo y represivo régimen militar porque los partidos y sus equipos técnicos no habían preparado un programa alternativo que tuviera elementos para corregir el desmantelamiento del Estado benefactor y empresario.

\section{TODO ATADO Y BIEN ATADO}

Los cambios institucionales en el sistema económico, en la educación y en la política, así como los nuevos valores que debían asumir los chilenos, fueron asegurados en la Constitución de 1980 para que no fueran reformados cuando los militares decidieran volver a sus funciones propias. Esta Constitución fue redactada siguiendo un concepto ajeno a la democracia pluralista, el de la "democracia protegida", que sería una alternativa a aquella, que habría sido débil frente al comunismo y el terrorismo.

8. Destacaban Enrique Silva Cimma, ministro de Relaciones Exteriores que había sido profesor de Derecho Administrativo; Francisco Cumplido, ministro de Justicia que había sido Secretario General de la sede occidente y profesor de Derecho Constitucional; Juan Agustín Figueroa, ministro de Agricultura y anteriormente profesor de Derecho Procesal; y Sergio Molina, ministro de Planificación y Desarrollo que fue decano de la Facultas de Ciencias Económicas. 
Este concepto se expresó en la tutela militar sobre las instituciones representativas, el pluralismo limitado (art. $8^{\circ}$ ), en la visión crítica de la soberanía popular y la hostilidad hacia el rol de los partidos; una visión corporativista del derecho de asociación, que, además, es crítica de los que tienen los trabajadores e impone un sistema económico, de orientación neoliberal.

Los constituyentes aseguraron la continuidad de esta arquitectura institucional, estableciendo "supramayorías" (Sierra y Mac-Lean, 2011) para impedir su reforma en el futuro por una mayoría y para limitar que esta apruebe proyectos de leyes que puedan modificarla. Para la reforma constitucional se requiere las tres quintas partes de los diputados y senadores en ejercicio y de dos terceras partes para ciertos capítulos de esta. Para la aprobación de proyectos de leyes referidas a importantes materias se exigen mayorías especiales. Para las "leyes orgánicas constitucionales", que tienen que ver con la organización de las Fuerzas Armadas, la organización de las elecciones y la educación, entre otros, se requiere un quórum de cuatro/séptimos de los senadores y diputados ${ }^{9}$.

Para las leyes de "quórum calificado", entre las cuales están las que rigen la actividad empresarial del Estado y la regulación del derecho a la seguridad social, entre otras, se exige la mayoría absoluta de los legisladores en cada una de las cámaras. El régimen autoritario aprobó las leyes orgánicas constitucionales antes de su término, apenas dos semanas antes en el caso de la referida a las Fuerzas Armadas ${ }^{10}$, y la Ley Orgánica Constitucional de la de Enseñanza (LOCE), que regula un tema de enorme importancia política, y que fue promulgada el 10 de marzo de 1990, un día antes de la inauguración de la democracia.

Las "supramayorías" fueron reforzadas después del plebiscito de 1988 con la adopción del sistema electoral binominal, que permite a la minoría obtener hasta la mitad de los escaños elegidos y, con ello, estar en una ficticia igualdad de representación que la mayoría, lo que constituye un sistema único en el mundo ${ }^{11}$.

La oposición (¿no es ahora oficialismo?) se ha negado a dar el consenso para tener una nueva Constitución, defendiendo la continuidad de la de 1980 y aceptando reformas que no alteran principios fundamentales de esta. Las más importantes fueron las de $1989^{12}$, después del plebiscito de 1988, negociadas entre la oposición y el régimen militar que derogó el artículo $8^{\circ}$ y matizó la tutela militar, y la de $2005^{13}$, que eliminó los senadores designados y vitalicios y restableció la autoridad del presidente sobre las designaciones y destituciones de los altos mandos de las FF.AA. Sin embargo, se

9. Las leyes orgánicas constitucionales de Francia y España, en las cuales se inspiraron los constituyentes de 1980, abarcan un número menor de materias y solo exigen una mayoría absoluta para su aprobación. Véase Pérez Royo (1995).

10. Fue promulgada el 27 de febrero de 1990

11. Sobre el origen, distintas posiciones de los partidos y los académicos y las implicancias del binominal, véase los artículos en Huneeus (2006).

12. Sobre esta reforma, véase Andrade (1991).

13. Sobre la reforma constitucional de 2005, véase Zúñiga (2005). 
mantuvieron componentes de la democracia protegida, como las "supramayorías", la visión negativa en la regulación de los partidos, los componentes corporativistas del derecho de asociación y la visión neoliberal del sistema económico ${ }^{14}$. La de 1980 es la Constitución con más reformas de la historia de Chile, pues "en sus casi 100 años de vigencia, (la Constitución de 1833) fue reformada 12 veces, mientras que la de 1925, en cerca de 50 años sólo experimentó 10 reformas y la de 1980, en su breve existencia desde que empezó a regir en 1990, ha sufrido ya 18 reformas" (Ríos Álvarez. 2006: 2).

\section{LEGADOS DE LA MODERNIZACIÓN ECONÓMICA EN CONTEXTO AUTORITARIO}

No es indiferente el contexto político en que la modernización económica comienza, porque ahí surgen instituciones, redes de poder y estilos de comportamiento que perduran en el tiempo, sobreviviendo a los cambios de regímenes políticos e influyendo en la orientación de un nuevo orden político. En este proceso destacó el surgimiento de un empresariado comprometido políticamente con un sistema económico neoliberal que desconocía el rol regulador del Estado, consideraba los derechos de los trabajadores subordinados al capital y miraba con desconfianza a la democracia, temiendo perder las enormes ventajas obtenidas en esos años. Esta fue una gran diferencia con otras transiciones, como la del Brasil, en la cual los empresarios apoyaron la democratización y miraron con optimismo la democracia, esperando tener un escenario más favorable para el desarrollo de la economía y, por ello, de sus intereses (Cardozo, 1988). Esto creo condiciones que favorecieron el desarrollo de un empresariado vinculado estrechamente a la política e identificado con ese orden político, lo que estableció una baja autonomía del orden económico respecto del orden político.

Esta identificación política del empresariado con el régimen militar se extendía al general Pinochet, admirado por haber salvado al país del comunismo y por ser el padre del "milagro" económico, pues el empresariado sabía que sin ese tipo de orden político habría sido imposible la transformación económica. Lo anterior se mantuvo y expresó en los años de la democracia porque el general Pinochet continuó ocho años como comandante en jefe del Ejército, no para ayudar a la consolidación de la democracia, sino para obstaculizarla (Agüero, 2006), y buscó impedir que se hiciera verdad y justicia por

14. El presidente Lagos consideró que esta reforma establecía una Constitución democrática, la de 2005, para lo cual el texto oficial lleva su firma y la de sus ministros y elimina la del general Pinochet y sus ministros, que acompañaban a la de 1980. En el discurso que pronunció en una ceremonia en la cual se promulgó la reforma, Lagos declaró: "Este es un día muy grande para Chile. Tenemos razones para celebrar. Tenemos hoy por fin una Constitución democrática, acorde con el espíritu de Chile, del alma permanente de Chile, es nuestro mejor homenaje a la independencia, a las glorias patrias, a la gloria y a la fuerza de nuestro entendimiento nacional". Véase al respecto http: //www.cooperativa.cl/ lagos-reformas-son-el-mejor-homenaje-a-las-glorias-patrias/prontus_nots/2005-09-17/122141.html, tomado el 23.8.2012. Sin embargo, esa aspiración no se ha impuesto y los partidos de la Concertación plantean la necesidad de tener una nueva Constitución. 
los atropellos a los derechos humanos. Su continuidad tuvo un efecto devastador en la cultura cívica porque la mayoría de la población, especialmente los que votaron contra él en el plebiscito de 1988, no comprendían que siguiera ocupando el principal cargo en el Ejército y no abandonara la política. Su presencia dañó la imagen de la democracia ante los ciudadanos, que debían convivir con el dictador.

Estas condiciones contextuales plantearon problemas bastante más difíciles que la evaluación hecha por Juan Linz y a Alfred Stepan (1996, pág. 211), cuando concluyeron que "políticamente, la democracia en Chile comenzó bajo las más severas restricciones constitucionales que en ningún otro país de América Latina o el sur de Europa".

La admiración hacia el general Pinochet era generalizada en la comunidad empresarial. En una entrevista realizada en 1997 por una revista económica de amplia circulación nacional a 28 destacados empresarios, 14 de ellos nombraron al general Pinochet como el chileno que más admiraban ${ }^{15}$. Entre estos se encontraba el ex presidente de la máxima organización empresarial -la Confederación de la Producción y el Comercio-y presidente de una de las mayores empresas del país, ENERSIS, un ex presidente de la influyente Sociedad de Fomento Fabril (SFF), que agrupa a los empresarios industriales, el presidente de la Compañía de Telecomunicaciones de Chile (CTC), la mayor de esta industria, y otros importantes hombres de negocios. Durante 1997, cuando el general Pinochet había iniciado una cuidadosa campaña para abandonar con honores el cargo de Comandante en Jefe, que había ejercido ininterrumpidamente desde fines de agosto de 1973, y se preparaba para continuar actuando en política para asumir como "senador vitalicio", dos importantes gremios, la Sociedad Nacional de Minería y la Cámara Nacional de Comercio ${ }^{16}$, lo condecoraron por sus servicios prestados al país en ceremonias públicas que fueron ampliamente difundidas por los medios de comunicación.. La Cámara Nacional de Comercio le concedió el premio "Diego Portales Palazuelos", en un acto que formó parte de las celebraciones del comercio. Según la información de prensa, el presidente de la entidad gremial, Alfonso Mujica, "agradeció al ex Presidente por todo lo que dio al país al sentar las bases para su progreso y bienestar y desarrollo económico y social"17.

Cuando permaneció detenido en Londres entre el 16 de octubre de 1998 y el 2 de marzo del 2000 por una resolución de la justicia de España que lo inculpaba por las violaciones a los derechos humanos, las organizaciones empresariales no solo condenaron las decisiones de los gobiernos de España e Inglaterra, sino que expresaron el apoyo al general Pinochet. El presidente de la Confederación de la Producción y el Comercio

15. En Capital, № 12, julio de 1997, págs. 33-37. Véase también Capital, № 19, enero de 1998, con portada del general Pinochet y con un largo artículo de su ex- ministro, Francisco Javier Cuadra: "Pinochet, el hombre, el militar, el político", págs. 14-21.

16. La decisión de la Sonami tuvo graves consecuencias, porque fue rechazada por los ejecutivos de las grandes empresas mineras extranjeras, que formaron el Consejo Minero, una iniciativa a la cual se incorporó Codelco y ha sido el principal interlocutor del Gobierno para los temas de la minería.

17. "Comercio distinguió a ex presidente Pinochet con premio Diego Portales", en El Mercurio, B1, 7 de junio de 1997. 
viajó a la capital británica para llevarle la solidaridad de los empresarios ${ }^{18}$. Y la Sofofa publicó una inserción en la prensa valorando la labor del régimen militar ${ }^{19}$.

\section{LA FUSIÓN DE LOS INTERESES PÚBLICOS Y PRIVADOS Y LA PRIMACÍA DE ESTOS}

Decíamos que la modernización económica impulsada por el régimen autoritario buscó fusionar los intereses público-privados en las actividades económicas y no terminó con la transición a la democracia, sino que continuó, incluyendo sus rasgos negativos impuestos por el contexto político, aunque sin los extremos alcanzados en el autoritarismo. Esta fusión se manifestó en democracia de múltiples partes y maneras, una de las cuales fue la puerta giratoria de ex ministros y altos funcionarios de Gobierno que pasaron a trabajar en o con el sector privado, como altos ejecutivos o empresarios, desarrollando una intensa labor en el campo de las comunicaciones, la asesoría política y el lobbismo; trabajando, por un lado, para el Gobierno y los partidos y, por otro, atendiendo primeramente los intereses del sector privado. Las universidades privadas no se mantuvieron ajenas a la puerta giratoria e integraron a los ex funcionarios a sus directorios como vicerrectores, decanos y hasta rectores, creando un entramado de relaciones económicas y personales que refuerza la continuidad del espacio privado en la educación. Esos ex funcionarios cumplen la función de intermediarios entre los intereses de sus clientes o de las empresas y los del Gobierno, que beneficia a los primeros. El dinamismo del sector privado y la politización de sus ejecutivos y socios controladores dio origen a esta enorme capacidad de cooptación de ex funcionarios de Gobierno.

Estas relaciones de mercado hacen posible la creación de nuevas bases de poder e influencia para este sector de élite formado por ex funcionarios de los gobiernos, que se desarrolla con autonomía de los partidos y que busca influir en estos, en el Gobierno y en la labor legislativa, para lo cual colabora con partidos y candidatos con el propósito de conseguir financiamiento para las campañas electorales.

Se dan justificaciones políticas para legitimar esta fusión, porque ellas ayudarían al desarrollo político y económico del país y porque se requiere de ciertas habilidades que solo los protagonistas de la transición tendrían para hacerlo posible. Al preguntarle a

18. Los dirigentes de la Confederación de la Producción y el Comercio han criticado el proceso de desafuero seguido en contra del general Pinochet, que terminó con un fallo de la Corte Suprema que lo condenó, sosteniendo que no favorece a la confianza necesaria para el desarrollo de la economía. El presidente de la Confederación de la Producción y el Comercio (CPC) pidió romper relaciones con Gran Bretaña, "W. Riesco pide romper relaciones diplomáticas con Gran Bretaña", en El Mercurio, 1 de julio de 1999.

19. En la declaración expresó "su reconocimiento al Gobierno de las Fuerzas Armadas que permitió recuperar el funcionamiento del orden social y establecer un marco económico moderno". "La Sociedad de Fomento Fabril frente a la detención en Londres del senador Augusto Pinochet Ugarte", en El Mercurio, 2 de diciembre de 1998. El presidente de la SFF, Felipe Lamarca, fue director del Servicio de Impuestos Internos entre 1978 y 1983. 
uno de los ex ministros más destacados de la transición, militante del PS, que se convirtió en un exitoso empresario y en un importante actor político, qué factores lo llevaron a dar ese paso, lo explicó así:

Fue la certeza de que el progreso se juega en la cooperación público-privada. Si nos involucramos en un largo conflicto entre estos dos sectores, el país se estancará y volveremos a días aciagos. Generar sólidos vínculos entre esos dos mundos no es automático y requiere de facilitadores profesionales con destrezas negociadoras y conocimientos de las políticas públicas y del mercado (subrayado nuestro) ${ }^{20}$.

Se genera así un círculo vicioso de negativas consecuencias para el desarrollo político, pues acentúa la baja autonomía de este respecto del poder económico. Lo anterior tiene múltiples consecuencias en el sistema político, en el que destaca la falta de voluntad para aprobar el financiamiento público de los partidos porque estos individuos cumplen funciones de apoyo al financiamiento de candidatos y partidos. Lo anterior también tiene consecuencias en la agenda pública, con temas vetados por el sector privado, como el tributario y el laboral. En Chile se puede discutir ampliamente sobre diversos temas de la agenda valórica, pero no se discute sobre los temas económicos, por el poder de veto que existe desde el sector privado.

No fue casual que el líder de la derecha que llegó a La Moneda el 2010, Sebastián Piñera, fuera un hombre de negocios y no un político profesional, además de una de las cinco principales fortunas del país, con inversiones en múltiples actividades, desde un canal de televisión, hasta en la sociedad Blanco y Negro, que controla el club de fútbol Colo Colo, el más popular ${ }^{21}$.

\section{RECUPERACIÓN Y REESTABLECIMIENTO DE LA DEMOCRACIA}

Cuando el 11 de marzo de 1990 se constituyó el Congreso elegido en diciembre de 1989 y asumió el nuevo mandatario, Patricio Aylwin (PDC), Chile recuperaba su antigua tradición democrática. Sin embargo, no podía restablecer la democracia que tenía antes del Golpe militar de 1973 no solo porque el país había cambiado profundamente en los 17 años de la dominación autoritaria, sino también porque el régimen militar no cayó, como en otros países de América Latina, sino que terminó de acuerdo a un proceso de reforma (Linz y Stepan, 1996), siguiendo la institucionalidad establecida por el régimen anterior, que impuso enormes limitaciones a la democratización. En estas, sobresalía la continuidad del general Pinochet como comandante en jefe del Ejército por ocho años, quien simbolizaba el doble carácter del régimen que presidió: de represión

20. Entrevista de Patricia Politzer a Enrique Correa, ex ministro Secretario General de Gobierno del presidente Patricio Aylwin, en Qué Pasa, 4 de julio de 2008, págs. 11-12.

21. Había entrado a la política con las primeras elecciones de 1989, siendo elegido senador (1990-1998), presidente de su partido (2003-2004) y candidato presidencial (2005 y 2009). 
y modernización económica; dos caras estrechamente ligadas entre sí porque no habría sido posible llevar ese tipo de cambio económico en un contexto democrático. Su permanencia en la dirección de la principal rama de las FF.AA. implicaba un poderoso respaldo a la continuidad de la transformación económica. Él contaba con apoyo del empresariado, de una parte de la población y de los parlamentarios de la UDI y RN, que le miraban como un ex presidente y no como un simple líder militar.

Las limitaciones institucionales impuestas por el régimen anterior, especialmente las "supramayorías", no agotan los factores que impidieron que Chile restableciera su tradición democrática. Las instituciones pueden limitar las opciones que tienen los actores, pero no las determinan (Alter, 1970), siendo estos los que deciden qué hacer en un difícil escenario político. Un ámbito de la gestión de Gobierno, como el económico, fue adoptado de consenso, sin interferencia de los enclaves autoritarios. Algunos de estos, como la continuidad del general Pinochet como comandante en jefe del Ejército después de 1990, fueron acentuados en sus alcances por malas señales por parte de algunas autoridades del Gobierno y del Congreso, que se propusieron domesticarlo con actitudes de diálogo y hasta de negociación y compromiso cuando presionó hasta el límite de la legalidad ${ }^{22}$.

No había en la Concertación la voluntad de hacerlo porque no existía un programa alternativo que lo justificara y se subestimaron las implicancias políticas que tuvo la transformación económica.

La Democracia Cristiana, el principal partido de la oposición, privilegió una opción política que puso a la gestión económica como la principal preocupación y en ello enfatizó más la continuidad que la reforma del sistema económico impuesta por el régimen militar. En esa tendencia, tuvo un rol destacado el equipo de economistas que reunió Alejandro Foxley en Cieplan y que llevó al Gobierno a colaborar con él desde el Ministerio de Hacienda. Foxley no había formulado un programa alternativo al impuesto por los Chicago Boys, que vinculara los cambios en la economía con los que debían realizarse en el sistema político, como lo había hecho Jorge Ahumada (1957) para la candidatura presidencial de Eduardo Frei Montalva en 1958 y 1964. Foxley y Edgardo Boeninger no consideraron las implicancias del desmantelamiento del Estado benefactor y empresario y su reemplazo por un dominio privado, sin que se hubieran establecido contrapesos al capital privado.

Descuidaron las bases económicas que hacen posible una democracia estable y de calidad, pues las que tenía Chile en 1990 eran positivas en el corto plazo, con una economía que estaba creciendo y contaba con un empresariado dinámico, pero eran débiles a mediano y largo plazo, por su dependencia en la explotación de los recursos naturales, en la concentración de los activos y la riqueza y en las desigualdades del ingreso; una de las peores en el mundo. Según el Latinobarómetro 2011, Chile tiene la peor percepción de distribución de ingresos según sus habitantes: solo un $6 \%$ cree que hay

22. Por este motivo no comparto la interpretación de Manuel Antonio Garretón (1989; 1995) sobre el impacto de los "enclaves autoritarios" para impedir que haya una democracia completa, porque tiene un cierto determinismo institucional. 
una distribución "muy justa" o "justa", en tanto la media de los 18 países de América es más del triple de ese porcentaje, es decir, de un $20 \%{ }^{23}$. La demanda por la igualdad que predomina en la sociedad chilena tiene sólidos fundamentos en las bases económicas y políticas de la democracia. (Gráfico 1)

\section{Gráfico 1}

LA OPCIÓN ENTRE LIBERTAD INDIVIDUAL E IGUALDAD SOCIAL, 1989-2011

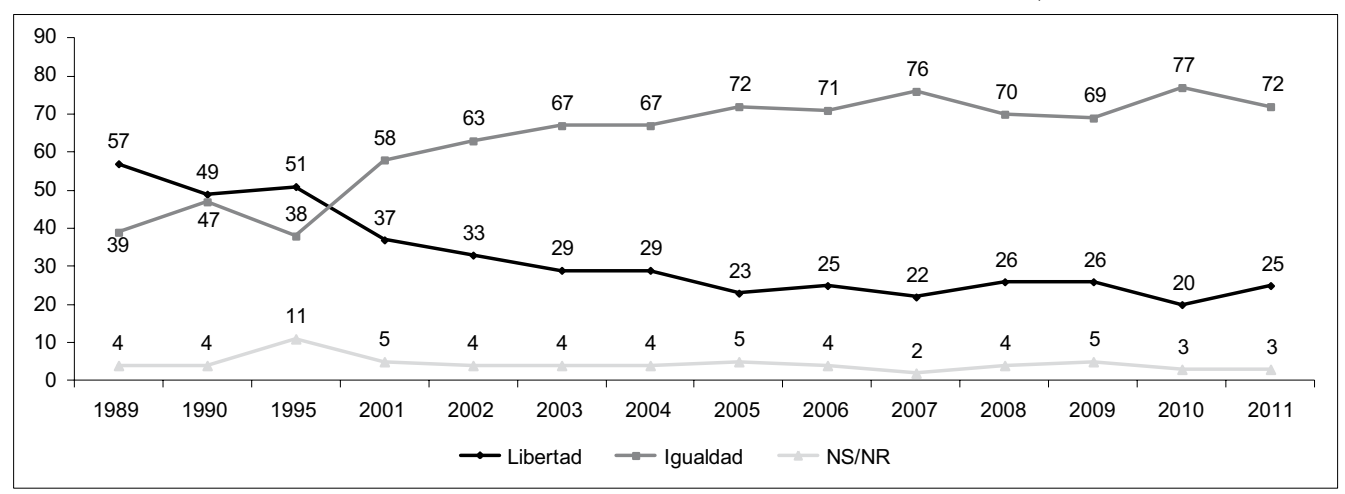

Fuente: Barómetros CERC, 1989-2011.

La democracia también requiere grupos de interés, que son organizaciones que complementan "la democracia electoral", pues "los votos cuentan en las opciones del personal de gobierno, pero otros recursos deciden en los hechos las políticas seguidas por las autoridades" y los grupos de interés, que tienen poderosas organizaciones, con las cuales influyen en las decisiones públicas, hacen "imposible gobernar por el principio 'más de 50 por ciento”. (Rokkan, 1966: pág. 106).

Los partidos de izquierda tampoco tuvieron una alternativa programática propia, que fuera más allá de la autocrítica al Gobierno de la Unidad Popular, y asumieron la nueva realidad constituida por el desplome de los socialismos reales, que se precipitaba cuando comenzaba la transición chilena, pues el muro de Berlín caía un mes antes de las primeras elecciones de diciembre de 1989. Banderas tradicionales de sus partidos, como la igualdad y la participación, fueron descuidadas ante un afán de ganar legitimidad como alternativa de Gobierno ante el mundo empresarial y hasta con los militares, cuando Pinochet todavía era comandante en jefe. Se abandonó la preocupación histórica de la izquierda por los trabajadores, cuyas organizaciones estaban muy debilitadas por el régimen militar. Sus dirigentes, y los intelectuales de sus partidos, dejaron de referirse a los trabajadores, como si ellos no existieran, optando por referirse a los "movimiento sociales", especialmente de minorías, pero sin organizaciones que tengan poder para influir en la agenda pública. Se defienden los derechos de la mujer, pero no hay especial

23. Uruguay y Costa Rica, que tienen una tradición democrática comparable a la de Chile, tienen una opinión pública menos crítica, pues $27 \%$ y $24 \%$ considera que hay una "justa distribución del ingreso". Véase Latinobarómetro, 2011, www.latinobarometro.org 
énfasis en los derechos que debiera tener el trabajo, con abusos extremos en diversas industrias, desde las temporeras en la agricultura, hasta las que trabajan en el retail. El abandono de los partidos de la Concertación hacia el movimiento estudiantil fue una consecuencia de esta decisión. Tampoco desde la izquierda se reivindicó la importancia de restablecer espacios del dominio público, especialmente en la educación.

Estas tendencias en el PDC, en el PS y el PPD estuvo muy influida por sus economistas, los cuales, con escasas excepciones, tenían doctorados en universidades de los EE.UU. y desconocían las singularidades de la economía europea, en la que destacaba la economía social de mercado de Alemania, impulsada por la CDU después de la II Guerra Mundial y que era una alternativa al neoliberalismo, partido que apoyaba al PDC a través de la Fundación Konrad Adenauer. No se prestó atención a las funciones regulatorias de Estado, que habían sido estudiadas por los economistas de Cieplan bajo iniciativa de Oscar Muñoz (1993), sino que se enfatizó en el rol de los empresarios, especialmente en los grandes, que serían los únicos que tendrían las capacidades para desenvolverse en una economía global e incluso se dio reconocimiento a los empresarios surgidos de las privatizaciones del régimen militar, que se aprovecharon de las posiciones de autoridad que tenían en las empresas públicas que pasaron al sector privado ${ }^{24}$.

\section{LEGITIMACIÓN DE LA DEMOCRACIA POR EL DESEMPEÑO ECONÓMICO}

La política económica tuvo una enorme influencia en la agenda de los gobiernos democráticos porque la estrategia de consolidación de la democracia fue en torno a ella. La economía sería un factor decisivo para consolidar el orden político, entregando los medios materiales para atender las demandas de los cinco millones de pobres, el $40 \%$ de la población, lo que permitiría, además, mostrar la eficacia del Gobierno.

24. En una entrevista de 1997 a la revista Capital, el ex ministro y senador (1994-2010) Carlos Ominami (PS), afirmaba: "Me siento orgulloso de tener un sector empresarial potente, que compite en el mundo, que tiene presencia en Argentina, Bolivia, que va a los mercados de los países más desarrollados y logrando competir con éxito". Iba bastante más lejos, porque ilustró su argumento mencionando a uno de los empresarios más controvertidos, José Yuraszeck que, de funcionario de Odeplan en Coyhaique, se convirtió en el controlador de Endesa y Chilectra en los años 80, formando el holding Enersis y llegó a ser el "zar de la electricidad" en los 90:

"Si hubiera habido un Yuraszeck en los años 30, la Corfo no habría hecho la Endesa... Creo que se hicieron todas las empresas no por un prurito simplemente estatista, sino porque no había un sector privado con espaldas capaces de desarrollar esas actividades".

Yuraszeck, con el apoyo de un grupo reducido de altos ejecutivos, vendió en 1997 sus derechos a la empresa española Endesa, en una controvertida decisión pues en las negociaciones privilegiaron los intereses propios y no el de los accionistas minoritarios, sin informar tampoco al directorio de la empresa de ellas. Por esos motivos, fueron sancionados por la Superintendencia de Valores y Seguros al pago de multas que fueron las más altas en la historia del país. Véase Huneeus (2007). 
Esto rompería la memoria del fracaso económico del Gobierno de la Unidad Popular y mostraría a partidos de izquierda con capacidad de guiar el país y su economía. La conducción responsable en el ámbito económico había faltado en la gestión de los primeros gobiernos democráticos en América Latina, con una hiperinflación que puso en peligro el regreso de los militares al poder ${ }^{25}$. El crecimiento entregaría bienes materiales que ayudarían a la legitimación de la democracia, porque mostraría eficacia para resolver las necesidades de la población. Se recogía así una antigua tradición sobre las relaciones entre el crecimiento y la democracia, que miraba sus efectos positivos sin considerar las precondiciones para que ello ocurriera, comenzando porque hubiera una buena imagen de los protagonistas del crecimiento, los empresarios, y por la percepción ciudadana sobre la distribución de los beneficios de aquel. Los empresarios, por el contrario, tienen una mala imagen (Cuadro 1) y la eficacia de la democracia se debilitó con el correr del tiempo, incluso en los años en que hubo más crecimiento, hasta 1998. (Gráfico 2)

\section{Gráfico 2}

SATISFACCIÓN CON LA DEMOCRACIA, LEGITIMIDAD Y EFICACIA, 1989-2011

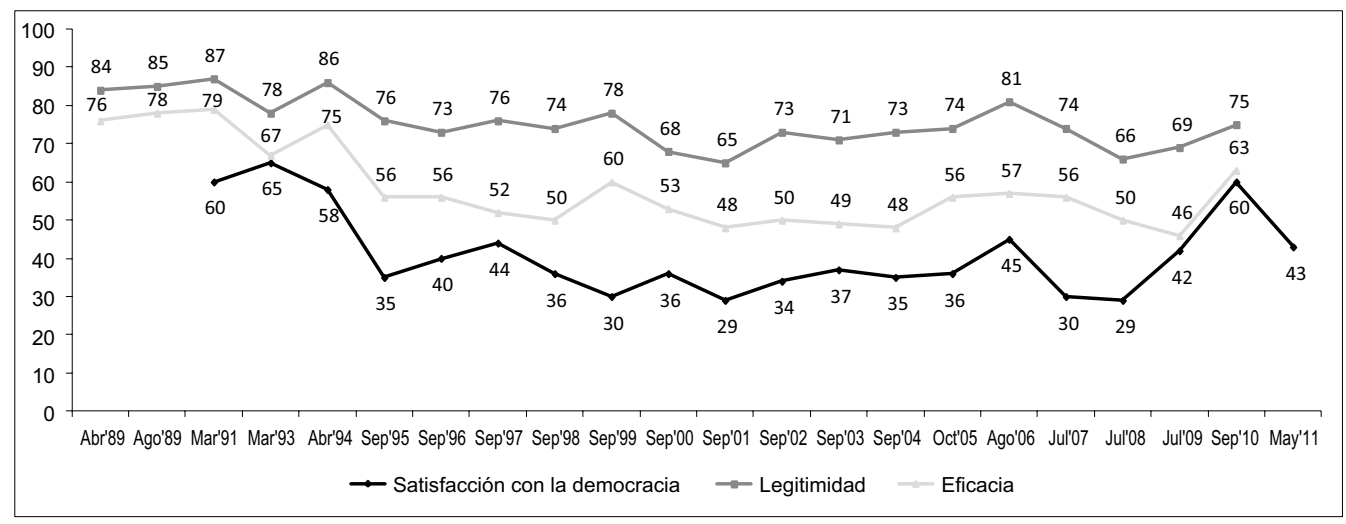

* Legitimidad: Acuerdo con la frase: "La democracia es el mejor sistema político para un país como el nuestro".

Eficacia: Acuerdo con la frase: "La democracia permite que se solucionen los problemas que tenemos los chilenos"

Satisfacción: Respuestas muy y bastante satisfechos con la democracia.

Fuente: Barómetros CERC, 1989-2011.

25. Fueron los casos del Perú, Brasil y Argentina. En este último país durante el gobierno del presidente Raúl Alfonsín (1983-1989) la grave crisis económica llevó a la derrota del candidato de su partido en los comicios presidenciales de 1989 y debió entregar el poder al presidente electo, Carlos Menem, antes del período constitucional para evitar un empeoramiento. Este Gobierno fue seguido muy de cerca por los economistas de la Concertación. Juan Sorrouille, que fue ministro de Economía, viajó a Chile a reunirse en Cieplan con economistas de la oposición, oportunidad en la que contó su difícil gestión en el gobierno de Alfonsín. Entrevista con Ricardo Ffrench-Davis, que participó en el encuentro. 


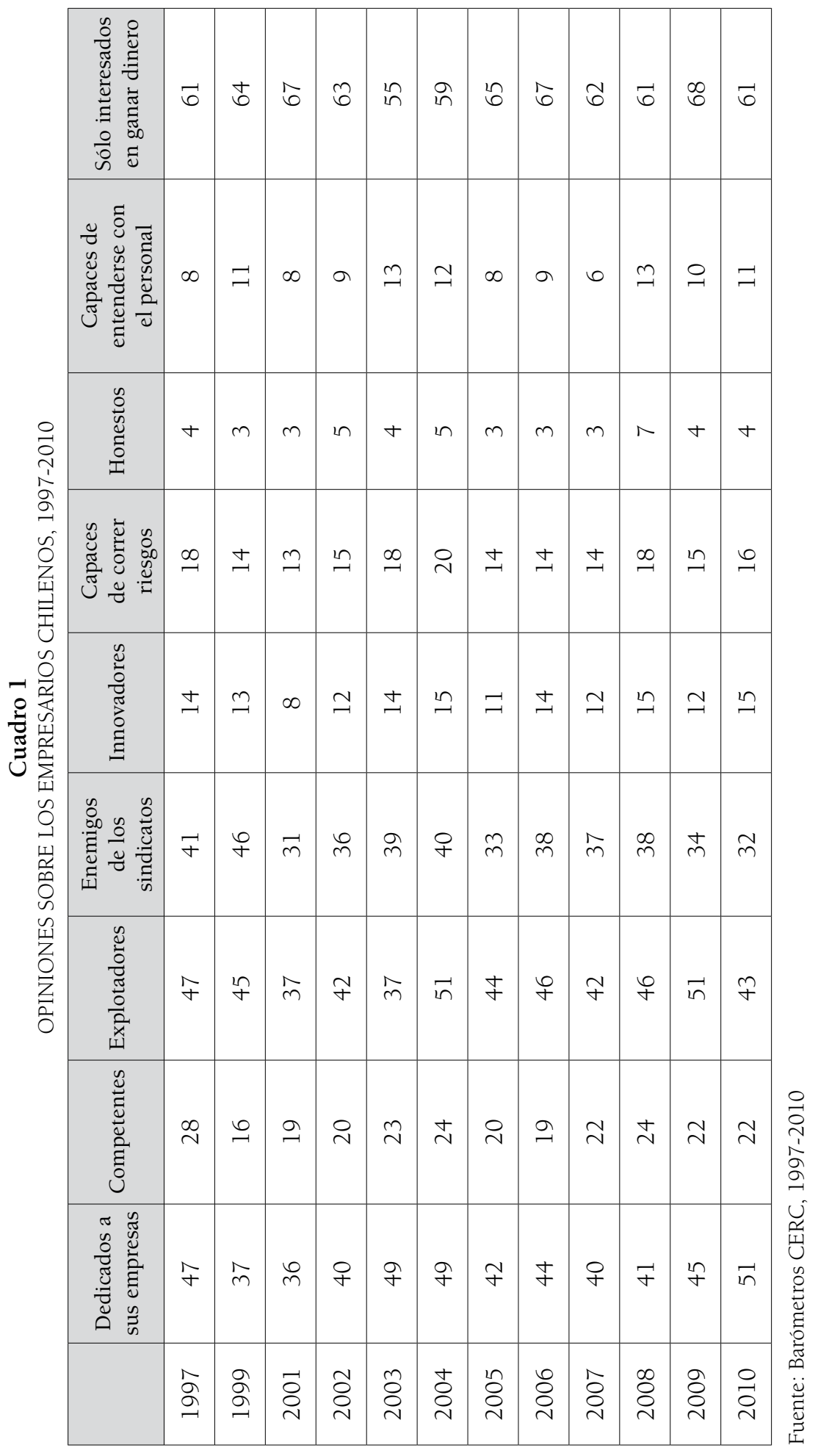


Fue el programa de "crecimiento con equidad" el que, en algún momento durante el Gobierno del presidente Eduardo Frei Ruiz-Tagle (PDC) (1994-2000), evolucionó hacia uno de crecimiento a secas, enfatizando la privatización y reafirmándose luego por el Gobierno del presidente Ricardo Lagos, el primer mandatario socialista después de Salvador Allende. Gobiernos de centro-izquierda aparecían impulsando políticas que no se diferenciaban de las impulsadas por administraciones de centro-derecha y no apuntaban a un desarrollo que hiciera posible una democracia de calidad.

La economía chilena en 1990 no era como la alemana: una poderosa mediana y pequeña empresa que concentra el empleo y constituye un factor poderoso de su dinamismo económico, neutralizando el poder de las grandes empresas y consorcios, lo que permite un desarrollo político centrista (Schmidt, 2006). La economía chilena, en cambio, estaba fuertemente concentrada, proceso que se acentuaría en la democracia con una gran concentración de la propiedad de los activos "en grupos económicos reducidos que pueden ser fuente de poder monopólico u oligopólico abusivo" (Molina, 2005). Los cinco grupos de mayor tamaño eran dueños de casi el 50\% de los activos de las empresas que se cotizaban en la bolsa y el grupo de mayor tamaño tenía el 20\% de los activos totales (Molina, 2005). La concentración es muy alta en los principales sectores de la economía, desde los bancos y las AFP, hasta el retail.

La concentración de la riqueza sobresale en el contexto latinoamericano. Andrés Solimano (2012) ha llamado la atención de la información reunida por la revista Forbes, con cuatro familias o individuos entre los súper-ricos del mundo, más que los que tiene cualquier otro país latinoamericano, y una riqueza acumulada de 42.5 billones de dólares, que en un país con una población cercana a los 17 millones de personas, representa alrededor del 21\% del PIB en 2010. Uno de estos individuos es el presidente Sebastián Piñera ${ }^{26}$, cuya elección en 2010 pone de manifiesto las estrechas relaciones entre el mundo de los negocios y la actividad política, pues entró a la política después del plebiscito de $1988^{27}$, siendo ya un exitoso hombre de negocios.

No es indiferente para la calidad de la democracia cómo se distribuyen los activos y la riqueza en un país, porque ello crea condiciones que la perjudican; los que tienen mayor poder económico estarán en mejores condiciones para influir en las decisiones de Gobierno y en el Congreso en su beneficio, aumentando la concentración económica y de la riqueza. Como afirma Colin Crouch (2011, pág. 47) "es

26. Los cuatro grupos son: la familia Luksic (minería, financiero e industrias), con un valor neto de 19,2 billones de dólares, ubicado en el lugar 27; Horst Paulmann, 10,5 billones (sector retail), en el lugar 75; Eliodoro Matte y su familia (silvicultura y energía), 10,4 billones, en el lugar 77 y Sebastián Piñera (fideicomiso ciego), con 2,4 billones de dólares, en el lugar 488. Solimano (2012, cuadro 7.1). Se debiera agregar al grupo Angelini, no incluido por Forbes, muy importante en la celulosa, la energía y la pesca.

27. Piñera votó por el No y después del plebiscito pidió reunirse con Patricio Aylwin, presidente del PDC, quien lo recibió acompañado de Edgardo Boeninger, para plantearle su interés de entrar a la política con un puesto alto. Aylwin le planteó que, de hacerlo, debía partir de la militancia base. Piñera se fue a RN y fue designado inmediatamente jefe de la campaña presidencial de Hernán Büchi y candidato a senador en la lista de RN, logrando imponerse al candidato de la UDI, Hermógenes Pérez de Arce. 
muy difícil impedir que la riqueza económica no sea aprovechada para convertirla en poder político. Los ricos pueden usar sus recursos para financiar a políticos y a partidos que están de acuerdo con ellos, o disuadir a aquellos que discrepan para que cambien su posición".

El impacto del sistema económico en la democracia fue mayor, porque la lógica económica invadió la política, por lo cual se vio al votante más como un consumidor que como un ciudadano, sin lealtades partidistas, ignorando la memoria histórica en la sociedad chilena; un ciudadano que puede ser convencido a través del marketing. La privatización de la economía afectó también la política, con subcontratación de funciones de los partidos en consultoras y empresas, creyendo que los "productos" que entregaban eran de similar calidad al trabajo de los activistas y las organizaciones partidistas. El sistema político podía ser reformado -ha habido 19 reformas constitucionales, incluyendo la eliminación del voto obligatorio en 2009-, pero el sistema económico se mantiene alejado a los cambios.

Lograr simultáneamente el desarrollo económico y una democracia de calidad fue una aspiración de numerosas generaciones en la historia de Chile, que no lo consiguieron en el pasado, donde se logró un destacado desarrollo político, pero se alcanzó un bajo crecimiento económico, inferior al aumento de la población. Mirando la evolución histórica del país, el economista Aníbal Pinto (1958) escribió que había "gran contradicción entre el ritmo deficiente de la expansión de su economía y el desarrollo del sistema y la sociedad democrática", expresado en un "subcrecimiento en lo económico y el relativo sobreprogreso en lo político" (subrayado nuestro).

Desde 1990 Chile habría roto ese frustrante pasado, porque estaría alcanzando simultáneamente crecimiento económico y un exitoso desarrollo político. El país estaría al borde de llegar a la tierra prometida, buscada durante largos y difíciles años. Ha consolidado una democracia y ha tenido un crecimiento económico que ha disminuido la pobreza y permitido una mejor calidad de vida para los chilenos, pero lo anterior se ha llevado a cabo de una manera que ha perjudicado al desarrollo político.

En efecto, se ha producido un fuerte deterioro de la calidad de la política, expresado en la incapacidad de enfrentar importantes problemas y el desprestigio de los políticos y de los partidos. Hay una baja confianza en las élites y en las instituciones, incluso los tribunales de justicia, y un apoyo mediocre a la democracia, que llama la atención en comparación a otros países de la región que tienen menor crecimiento y tradición democrática (Huneeus, 2010; Huneeus y Maldonado, 2003). El país ha tenido un severo déficit en la calidad de la representación, pues los jóvenes no tenían ciudadanía política porque no se inscribieron en los registros electorales. El padrón electoral estuvo prácticamente congelado desde las elecciones de 1989, cuando el 89,9 \% de la población que estaba habilitada para ser ciudadana estaba inscrita en los registros electorales y cayó al 68,02 \% veinte años después. Esta caída no se reparte en forma homogénea en la sociedad, sino que refleja las desigualdades con una relativamente alta inscripción de los jóvenes de los estratos económicos altos.

Se ha producido un severo debilitamiento de los partidos como organización, con rupturas en el PS, PPD y PDC y con una brusca caída de su afiliación y ante el electorado. 
La caída de los encuestados indica preferencia de partido por debajo del 50\%, cuando era superior al $80 \%$ en los años 90 . Ello tiene importantes repercusiones en la calidad de la democracia, por las funciones que los partidos tienen en la agregación de intereses, en el apoyo a la gestión de los gobiernos y en la integración de los ciudadanos al sistema político (Dalton y Wattemberg, 2002).

En pocas palabras, el crecimiento económico no ha favorecido el desarrollo político y, peor aun, tiene elementos que lo perjudican, como las restricciones a la autonomía de la política respecto del poder económico por la ausencia de regulaciones que la separen de los negocios y la puerta giratoria de ex ministros y altos funcionarios trabajando en y con el sector privado para promover sus intereses.

La situación actual podría describirse como la inversa a la descrita por Pinto (1958: pág. 11): hay una "gran contradicción" constituida por un "sobreprogreso" en lo económico y un "subcrecimiento" en lo político. Esta "gran contradicción" se acentuó con el cambio de Gobierno de 2010 y la llegada a La Moneda del presidente Sebastián Piñera, porque se mantuvo las orientaciones de las políticas de los gobiernos de la Concertación, acentuando, en el caso de la educación, la tendencia hacia una mayor privatización, especialmente en la educación superior. Esto condujo a las masivas movilizaciones ciudadanas convocadas por las organizaciones estudiantiles el 2011, las cuales cuestionaron no solo la mala calidad de la educación superior y el lucro en ella, sino también el sistema democrático y las desigualdades del sistema económico. El conflicto con los estudiantes llevó a la caída de dos ministros, Joaquín Lavín (UDI), dos veces candidato presidencial, y Felipe Bulnes (RN).

El nuevo Gobierno ha impulsado una política de educación superior que ha hecho más difícil el escenario político para la Universidad de Chile, ello porque su preferencia es hacia un sistema en que las universidades privadas tengan un rol muy protagónico. Este énfasis se ha acentuado con el nombramiento como ministro de Educación del economista Harald Beyer, el tercer titular de la cartera, que había sido director académico y subdirector del Centro de Estudios Públicos (CEP), el principal think de centro-derecha y vinculado a las grandes empresas privadas. Durante su primer año, Beyer ha mantenido una postura crítica hacia el Consejo de Rectores (CRUCH) y las universidades estatales en general y hacia la Universidad de Chile, en particular.

Sin embargo, no es viable ni a mediano ni a largo plazo una mayor privatización de la educación superior sin que las universidades privadas den un salto cualitativo en calidad, lo cual pondría en jaque el rol del lucro en ellas. Su legitimación no basta por el desempeño; por el hecho de que centenares de miles de familias hayan podido entrar a la educación superior. Ella es de baja calidad en la mayoría de las instituciones y es impulsada principalmente por universidades privadas con fines de lucro, que son aceptadas por una minoría de la sociedad.

La crisis de la educación ha pasado a ser una parte del problema más de fondo que tiene la modernización económica de Chile desde la ruptura de 1973, que no tiene la legitimación suficiente para que tener eficacia y servir de apoyo al desarrollo político. La Universidad de Chile se encuentra en el centro de ese desafío y el cómo será resuelto incidirá de manera muy determinante en su futuro. 


\section{CONCLUSIONES}

El escenario en que se debe desenvolver la Universidad de Chile es difícil; con un sistema político del cual depende por ser estatal y que tiene una baja capacidad de reforma por el veto de la minoría, por la falta de consenso en los partidos de centro e izquierda de la importancia del "dominio público" (Marquand, 2005) y por la menor autonomía que tiene la política frente al poder económico. Esta última es una de las limitaciones más severas para conseguir una democracia de calidad en Chile, más que en otros países, entre otros factores por la falta de financiamiento de los partidos. La pérdida de identidad política de los partidos y la primacía de las alternativas tecnocráticas han debilitado la política y quitado apoyo a la defensa del dominio público. El apoyo a la educación pública se convierte más en una declaración que en acciones específicas y los pasos que se dan en esa dirección son compensados con beneficios a las universidades privadas.

La continuidad de la transformación económica que apunta a imponer la primacía del dominio privado está en crisis en varios sectores, comenzando por la previsión, que fue enfrentada con la reforma previsional de 2008 y que dio una respuesta a ello. Sin embargo, no la resuelve a mediano y largo plazo por las debilidades del sistema económico, con bajas remuneraciones e inestabilidad laboral, que apunta a bajas pensiones que crearán inseguridades en la población laboral y en los pensionados.

La educación superior tiene una fuerte oposición en sus estudiantes y en las familias de estos, junto a debilidades de fondo del sistema, que solo por razones ideológicas se pueden ignorar.

La experiencia comparada muestra que las democracias no se consolidan sin tener desarrollo político, con partidos y un Congreso con capacidad decisoria, organizados a partir de una Constitución genuinamente democrática que no impone un modelo económico de orientación neoliberal ni es hostil hacia los partidos al no reconocer las funciones que cumplen en democracia ${ }^{28}$. Un orden político puede imponer limitaciones a las generaciones futuras para asegurar su continuidad, estableciendo mayorías altísimas para impedir las reformas. Sin embargo, esa aspiración es ilusoria ante las presiones que surgen desde la sociedad, el sistema político pierde legitimación (Alexander, 2001) y esta no se consigue con instituciones económicas que de por sí tienen una baja legitimación.

28. La Constitución de 1980, en el artículo 19, № 15, mantiene el texto original en relación a los partidos, sin definir sus funciones, sino imponiendo limitaciones:

Los partidos políticos no podrán intervenir en actividades ajenas a las que les son propias ni tener privilegio alguno o monopolio de la participación ciudadana; la nómina de sus militantes se registrará en el servicio electoral del Estado, el que guardará reserva de la misma, la cual será accesible a los militantes del respectivo partido; su contabilidad deberá ser pública; las fuentes de su financiamiento no podrán provenir de dineros, bienes, donaciones, aportes ni créditos de origen extranjero; sus estatutos deberán contemplar las normas que aseguren una efectiva democracia interna. Una ley orgánica constitucional regulará las demás materias que les conciernan y las sanciones que se aplicarán por el incumplimiento de sus preceptos, dentro de las cuales podrá considerar su disolución. 
En este difícil escenario nacional tiene que actuar la Universidad de Chile y su destino, de una manera distinta al siglo XIX y que está cruzado con las soluciones que se den a la "gran contradicción" entre "sobrecrecimiento económico" y "subcrecimiento político".

\section{REFERENCIAS BIBLIOGRÁFICAS}

Ahumada, J., En vez de la miseria, Santiago: Editorial del Pacífico, 1957.

Alexander, G., "Institutions, Path Dependence, and Democratic Consolidation", en Journal of Theoretical Politics, Vol. 13,N³, 2001, págs. 249-270.

Agüero, F., "Democratización y Militares: Balance de Diecisiete Años desde la Transición", en Alcántara, M., Ruiz Rodríguez, Leticia M. (eds.), Chile: Politica y Modernización Democrática, Barcelona: Edicions Bellaterra, 2006.

Andrade Geywitz, C., Reforma de la Constitución Política de la República de Chile de 1980, Santiago: Editorial Jurídica de Chile, 1991.

Apter, D., Choice and the Politics of Allocation, New Haven: Yale University Press, 1970.

Collier, D. (comp.), The new Authoritarianism in Latin America, Princeton: Princeton University Press, 1979.

Crouch, C., The Strange Non-Death of Neoliberalism, Cambridge: Polity Press, 2011.

Dahrendorf, R., Lebenschancen, Frankfurt: Suhrkamp, 1979.

Garretón, M.A., La posibilidad democrática en Chile, Santiago: FLACSO, 1989.

- Hacia una nueva era política. Estudio sobre las democratizaciones, Santiago: Fondo de Cultura Económica, 1995.

Henrique Cardoso, F., "Los empresarios y el proceso de transición: el caso brasileño", en O`Donnell, G. Philippe, S., y Whitehead, L. (comps.), Transiciones desde un gobierno autoritario. 3. Perspectivas Comparadas, Buenos Aires: Paidós, 1988, págs. 213-235.

Huneeus, C., La reforma en la Universidad de Chile. Santiago, Corporación de Promoción Universitaria, 1973.

— La reforma universitaria en Chile veinte años después, Santiago: Corporación de Promoción Universitaria, 1988

- (comp.), La reforma al sistema binominal en Chile, Santiago: Fundación Konrad Adenauer/ Catalonia, 2006.

The Pinochet Regime, Boulder, Col.: Lynne Rienner, 2007.

— La guerra fría chilena. Gabriel González Videla y la ley maldita, Santiago: Random House Mondadori, 2009.

Huntington, S.P., Political Order in Changing Society, New Haven: Yale University Press, 1968.

Jiménez de la Jara, J., Angelitos salvados, Santiago: Uqbar, 2010.

Linz, J.J. y Stepan, A., Problems of Democratic Transition and Consolidation, Baltimore: The John Hopkins University Press, 1996.

Marquand, D., Decline of the Public, Cambridge: Polity Press, 2005.

Marshall, T.H., Class, Citizenship, and Social Development, Westport: Greenwood Press, 1973.

Molina, S., Es el tiempo de la equidad, Santiago de Chile: Academia Chilena de Ciencias Sociales, Políticas y Morales, Instituto de Chile y Banco del Desarrollo, 2005.

Muñoz, O. (ed.), Hacia el Estado regulador, Santiago: CIEPLAN, 1993.

Pérez Royo, J., Curso de Derecho Constitucional, Madrid: Marcial Pons, Ediciones Jurídicas S.A., 1995. 
Pinto, A., Chile, un caso de desarrollo frustrado, Santiago: Editorial Universitaria S.A., 1958.

Ríos Álvarez, L., "La gran reforma de la Ley No 20.050 a la Constitución Política de Chile", en Gaceta Jurídica, № 307, 2 de enero de 2006.

Rokkan, S., "Norway: Numerical Democracy and Corporate Pluralism", en Dahl, R. (ed.), Political Opposition in Western Democracias, New Haven: Yale University Press, 1966, págs. 70-115.

Rouquié, A., El Estado militar en América Latina, Buenos Aires: Emecé Editores, 1984.

- A la sombra de las dictaduras. La democracia en América Latina, Buenos Aires: Fondo de Cultura Económica, 2011

Sierra I., L., Mac-Clure, L., Frente a las mayorias: leyes supramayoritarias y Tribunal Constitucional en Chile, Santiago: CEP, Cieplan, Libertad y Desarrollo y ProjectAmerica, 2011.

Solimano, A., Capitalismo a la chilena, Santiago de Chile: Editorial Catalonia, 2012.

Zúñiga Urbina, F. (coord.), Reforma constitucional, Santiago: LexisNexis, 2005. 